\title{
Salmonellosis beyond the gastrointestinal tract: a case series
}

\author{
DLB Piyasiri' ${ }^{1}$ P Chandrasiri ${ }^{2}$, HS Jayasinghe ${ }^{3}$, S Pathirage ${ }^{4}$, PM Sapukotana ${ }^{1}$, TSH Gamage $^{1}$
}

Ceylon Medical Journal 2017; 62: 240-41

DOI: http://doi.org/10.4038/cmj.v62i4.8575

\section{Introduction}

Genus Salmonella is a member of the family enterobacteriaceae, and the disease salmonellosis is contracted through ingestion of contaminated food or water. It is associated with poor sanitation and lack of clean drinking water.

While Salmonella Typhi and Salmonella Paratyphi A, B, C are known to cause enteric fever, together with other Salmonella species (non typhoidal Salmonella) they can cause extra-intestinal disease or complications due to seeding of the bacterium in other organs following bacteraemia. The bacterium can affect anywhere in the body causing endocarditis, vascular infections, cholecystitis, hepatic and splenic abscesses, urinary tract infections including pyelonephritis, pneumonia, empyema, meningitis, septic arthritis and osteomyelitis. In this paper we describe extra-intestinal salmonellosis cases reported from different parts of Sri Lanka.

\section{Case report 1}

A 25 year old student presented with fever and headache of one week duration to National Hospital of Sri Lanka, Colombo, in October 2010. Blood culture became positive for Salmonella Paratyphi A and the patient was treated with IV ceftriaxone.

Although fever responded initially after few days it reappeared. Upon further investigations, mitral valve vegetation was detected. Ceftriaxone dose was increased to $2 \mathrm{~g}$ mane and $1 \mathrm{~g}$ in the evening (12 hours apart) and continued for 4 weeks followed by oral azithromycin $500 \mathrm{mg}$ daily for another week. Complete recovery was observed with the disappearance of vegetations.

\section{Case report 2}

A 7 month old boy presented with generalized tonic clonic convulsions with fever to District General Hospital Polonnaruwa in November 2013. About one month prior he had been treated for pyogenic meningitis for 2 weeks with IV ceftriaxone.
In the second admission too, his physical examination, white cell count (18.9x109/1), C reactive protein $(>96 \mathrm{mg} / \mathrm{l})$ and cerebrospinal fluid report were suggestive of bacterial meningitis and the CT brain showed left sided focal cerebritis. Blood culture became positive for Salmonella Group B.

Due to poor response to ceftriaxone, antibiotics were changed to IV meropenem $40 \mathrm{mg} / \mathrm{kg} 8$ hourly and IV chloramphenicol $25 \mathrm{mg} / \mathrm{kg} 6$ hourly. The patient responded to these antibiotics. After 6 weeks he was discharged and was followed up regularly in the clinic. Family was screened for Salmonella carrier status and was found to be negative.

\section{Case report 3}

A one month and 8 days old baby presented with high fever and convulsions to Teaching Hospital Karapitiya in August 2017. He had been treated for meningitis for 3 weeks with IV meropenem prior to the second admission. CT revealed cerebritis. Blood culture grew Salmonella typhimurium. He was treated for 8 weeks with IV chloramphenicol and IV meropenem until complete clinical resolution was obtained. Household contacts were screened for Salmonella carrier status and was found to be negative.

\section{Case report 4}

A 48 years old male from Sooriyawewa was transferred to Teaching Hospital Karapitya in May 2016 with pyelonephritis and septic shock. He had pyelolithotomy in 2007 for left sided ureteric and pelviureteric junction calculi with partial obstruction.

The total white cell count was 4.9x109/1 and CRP was $122.5 \mathrm{mg} / \mathrm{l}$ with a serum creatinine $333 \mathrm{micmol} / \mathrm{l}$. Ultrasound scan of the kidneys revealed bilateral renal calculi. Bilateral JJ stenting was done. Blood culture became positive for Salmonella typhimurium (group B). Patient was treated with a combination of IV meropenem and IV ciprofloxacin for 2 weeks and changed to oral azithromycin for one more week.

1 Teaching Hospital Karapitiya, Galle, 2National Hospital of Sri Lanka, Colombo, 3District General Hospital Polonnaruwa, 4Medical Research Institute, Borella.

Correspondence: DLBP, e-mail: <bhagyapiyasiri@yahoo.co.uk>. Received 09 September 2017 and revised version accepted 20 November 2017. and reproduction in any medium, provided the original author and source are credited. 


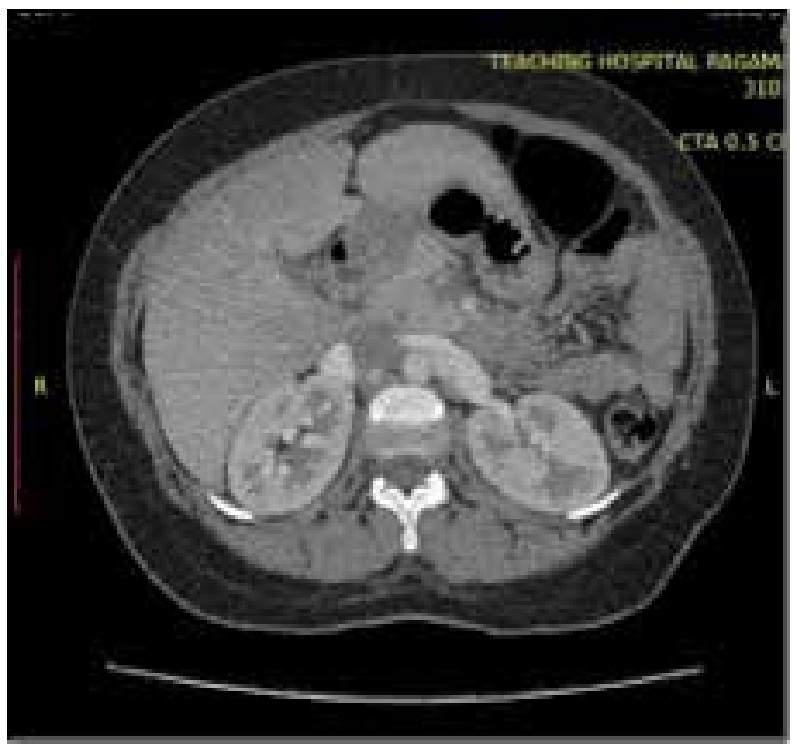

Figure 1. CT angiogram of the abdomen showing stenosis of the left renal vein anterior to the aorta

\section{Discussion}

\section{Endocarditis and vascular infections}

Endocarditis, pericarditis, valve perforation, and arteritis caused by Salmonella have been reported worldwide usually with a poor prognosis. In 2016, Cheng et al. reviewed 500 cases between 1976 and 2014 which comprised 87 cases of typhoid and non-typhoid Salmonella endocarditis with male predominance and mitral valve involvement in majority of cases $(33.3 \%)$. The overall mortality rate was $42.5 \%$ but it has decreased over time from $69 \%$ to $13 \%$ with the advancement of management [1].

Salmonella endcarditis is usually associated with a predisposing condition, such as rheumatic heart disease, diabetes, corticosteroid therapy, malignancy, HIV, drug abuse [2]. Several case reports suggest ceftriaxone as the drug of choice with or without gentamycin/azithromycin/ fluoroquinolone and that treatment should be continued for 4-6 weeks depending on the response.

Surgical removal of the infected valve may be necessary but our patient recovered fully with antibiotics alone which might have been due to younger age, lack of any predisposing conditions, early diagnosis and prompt treatment.

\section{Salmonella meningitis}

Worldwide Salmonella meningitis remains a threat to children aged less than 2 years [3]. In a study done in Kuala Lumpur by Lee et al. on Salmonella meningitis in infants, 13 infants presented with fits and complications such as hydrocephalus, subdural effusions, empyema, ventriculitis, intracranial haemorrhage and cerebral abscess [4]. Overall mortality rate was $13 \%-18 \%[3,4]$. The study further describes that relapses occurred due to inadequate treatment as might have happened in our cases as well.

\section{Salmonella urinary tract infections}

Urinary tract infection by Salmonella is usually associated with immunosuppression, chronic disease such as diabetes, structural abnormalities or renal stones. Haematogenous spread from gastroenteritis and seeding around the stones causing secondary bacteraemia is possible in our patient with pyelonephritis. Also the infective dose of the organism might have been reduced by the chronic pain killers with antacids use.

In a study by Jose $\mathrm{M}$ et al. of 28 cases of bacteriuria due to non typhoidal Salmonella, 16 had cystitis, 3 had pyelonephritis while 2 had renal abscess [5]. Salmonella enteritidis was the most frequently isolated $(n=16)$ followed by Salmonella typhimurium $(\mathrm{n}=5)$ as in our case.

\section{Conclusion}

Clinicians should understand the importance of taking blood for culture from patients with suspected salmonellosis before commencing antibiotics. Though the recommended drugs of choice are ceftriaxone or cefotaxime (in neonates), complications or poor response might require a different regime which is preferably a combination of sensitive antibiotics. Complicated extraintestinal infections may need an extended duration of antibiotics to prevent a relapse. Also early detection of complications and prompt action will improve the survival rates and reduce residual damage.

\section{Conflicts of interest}

Authors declare that they have no conflicts of interest

\section{References}

1. Cheng WL, Li CW, Li MC Lee NY, Lee CC, Ko WC. Salmonella infective endocarditis, J Microbiol Immunol Infect 2016;49(3): 313-320

2. Fernández Guerrero ML1, Torres Perea R, Gómez Rodrigo J, Núñez García A, Jusdado JJ, Ramos Rincón JM. Infectious endocarditis due to nonTyphi Salmonella in patients infected with human immunodeficiency virus: report of 2 cases and review, Clin Infect Dis 1996; 22:853-5

3. Wu HM1, Huang WY, Lee ML, Yang AD, Chaou KP, Hsieh LY. Clinical features, acute complications, and outcome of Salmonella meningitis in children under one year of age in Taiwan. BMC Infect Dis 2011; 11:30

4. Lee WS, Puthucheary SD, Omar A. Salmonella meningitis and its complications in infants. $J$ Paediatr Child Health 1999;35(4):379-82.

5. Ramos JM, Aguado JM, García-Corbeira P, Alés $\mathrm{JM}$, Soriano F. Clinical spectrum of urinary tract infections due to nontyphoidal Salmonella species. Clin Infect Dis 23:388-90 